\title{
The Akans of Ghana Indigenous Biodiversity Conservation Practices: Implication for Senior High School Curricula
}

\author{
Maxwell Jnr Opoku, Angela James \\ School of Education - Edgewood Campus, University of KwaZulu-Natal \\ Private Bag X03, Ashwood, 3605, Durban, South Africa \\ juniormaxi156@yahoo.com; jamesa1@ukzn.ac.za
}

\section{Extended Abstract}

For centuries, many indigenous cultural groups have through the value, care and respect for nature sustainably conserved biodiversity, lands and water resources; wholeheartedly without a feeling of being pressured and persuaded by government agencies of their country. Presently, however these innate indigenous cultural specific conservation practices of the people are fading away and on the verge of being eroded completely. Meanwhile there is a global outcry for conservation of biodiversity in the light of the alarming loss of biodiversity and their habitats [1-3]. The integration of indigenous biodiversity conservation practices into the formal school curricula may be crucial to the resuscitation of the long standing indigenous cultural biodiversity conservation practices that helped to keep the ecosystem undisturbed. And has possibility of enhancing general educational goals and objectives for conservation of biodiversity locally and globally.

This research was conducted in three local areas within the Ashanti Region of Ghana where majority of the Akan cultural group live. The areas were selected through consultation, information from other participants and through literature for reasons of being the hub of many custodians of the Akan culture and where indigenous Akan cultural practices are still relevant. These areas are Agona, Asaman and Ejisu. The researcher conducted 20 in-depth conversational 'semi-structured' interviews with custodians of the Akan culture (chiefs - 'ahenfo', traditional priest/priestesses 'akomfoo', traditional healers -'adunsifoo', the elderly - 'mpaninfoo', and youth -'mmerantee') and with relevant stakeholders of Secondary School Educational curriculum development (teachers and curriculum developers). Interviews centred majorly on their indigenous biodiversity conservation practices and sought for their views on integrations of such practices into Secondary School curriculum as well as their views with respect to how this integration could be done, and the prospects and challenges of such an integration. All the interviews were conducted in their local indigenous language (Asante-Twi language) as a way of preserving their indigenous language and make them feel at home.

Selection of participants was purposive and non-random applying snowball sampling technique. This was based on recommendations from consultations made at the relevant offices and other participants. All observations and interviews with participants occurred within their naturalistic socio-cultural context guided by the naturalistic inquiry ethnographic research style. Naturalistic in the sense that, the research was conducted in the participants' natural or real world context because the objective was to observe and describe the situations as they are. It was also ethnographic because the culture of the people was to be understood in their natural setting. Data generated are being analysed using the interpretivist paradigmatic approach [4-6].

During the data generation, participants mentioned some of their indigenous cultural practices and some worldviews on some wild plants and animals: use of taboos; 'evil days', spiritual powers inherent in some wildlife plants and animals; totemic powers; plants and animal that are approached as deities; some plant, animals and water bodies known to have presence of life of supreme being and ancestors; plants and animals known to communicate like humans; talking trees and talking to trees.

Almost all participants lamented the current denigration and gradual loss of their indigenous cultural practices citing reasons like technological advancement, modern educational systems, invasion of foreign religions like Christianity and Islam and disrespect for traditional authority. However, many of the participants were optimistic that if proper structures are put in place to demystify the wrong impression created about their culture by their past colonizers, these indigenous 
conservation practices could be revived and fully integrated into the formal school curriculum from the primary, through secondary and tertiary levels.

And that making such effort to put them into formal school curricula will revitalize it, make it appealing to the younger generation who would be most affected by the loss of biodiversity and their habitat if it continues at the rate it does. The integration stands the chance of helping to quicken the indigenous culture specific conservation practices. Participants also made suggestion for successful way of integration which includes having cultural days at schools, inviting resource persons in the form of custodians of the Akan culture into schools; school visiting indigenous reserved wildlife, forests and water resources. Nevertheless, many of the participants, perceived some challenges that would include the practicality, ontological and epistemological challenges regarding the transmission of the knowledge of these indigenous cultural conservation practices. The practicality (inexperienced and uninterested students, cultural diversity in schools, political support, centralised curriculum), ontological (beliefs as being superstitious, archaic) and epistemological (different knowledge systems and means of transmission). Additionally, the younger generation are prone to demand for in-depth explanation and experiments from custodians and experimentations to prove the validity of some of these indigenous cultural biodiversity conservation practices as reasons for some practices are still unknown.

Conclusively, the researchers believe that integration of indigenous cultural conservation practices may go a long way to complement current ways of conservation studied in our schools and would be in a good position to help reduce the alarming rate of biodiversity loss in the context of this study.

\section{References}

[1] E. D. Essien, "The Loss and Damage of Environmental Ethics in the Threshold of African Culture: Environmental Ethics and African Culture," International Journal of Knowledge Society Research (IJKSR), vol. 6, pp. 85-99, 2015.

[2] M. A. Masoga and H. O. Kaya, "African indigenous ecology control and sustainable community livelihood in southern African history," International Journal of African Renaissance Studies-Multi-, Inter-and Transdisciplinarity, vol. 9, pp. 6-19, 2014.

[3] M. R. Rands, W. M. Adams, L. Bennun, S. H. Butchart, A. Clements, D. Coomes, et al., "Biodiversity conservation: challenges beyond 2010," Science, vol. 329, pp. 1298-1303, 2010.

[4] J. Ritchie, J. Lewis, C. McNaughton Nicholls, and R. Ormston, Qualitative research practice: a guide for social science students and researchers, 2014.

[5] C. Bertram and I. Christiansen, Understanding research : an introduction to reading research. Pretoria: Van Schaik, 2014.

[6] I. Family Health, N. Mack, C. Woodsong, S. United, and D. Agency for International, Qualitative research methods : a data collector's field guide. North Carolina: FLI USAID, 2005. 